\title{
Biomarkers as therapy monitoring for postmenopausal osteoporosis: a systematic review
}

Filippo Migliorini ${ }^{1 *} \mathbb{D}$, Nicola Maffulli ${ }^{2,3,4}$, Filippo Spiezia ${ }^{5}$, Markus Tingart ${ }^{1}$, Peretti Giuseppe Maria ${ }^{6,7}$ and Giorgino Riccardo ${ }^{7}$

\begin{abstract}
Background: Biochemical markers of bone turnover (BTMs), such as bone alkaline phosphatase (bALP), procollagen type I N propeptide (PINP), serum cross-linked C-telopeptides of type I collagen (bCTx), and urinary cross-linked Ntelopeptides of type I collagen (NTx), are commonly used for therapy monitoring purposes for osteoporotic patients. The present study evaluated the potential role of BTMs as therapy monitoring.

Methods: All randomized clinical trials (RCTs) comparing two or more pharmacological treatments for postmenopausal osteoporosis were accessed. Only studies that reported the value of bALP, PINP, bCTx, and NTx at last follow-up were included. A multivariate analysis was performed to assess associations between these biomarkers and clinical outcomes and rate of adverse events in patients with postmenopausal osteoporosis. A multiple linear model regression analysis through the Pearson product-moment correlation coefficient was used.

Results: A total of 16 RCTs (14,446 patients) were included. The median age was 67 years, and the median BMI 25.4 $\mathrm{kg} / \mathrm{m}^{2}$. The median vertebral BMD was 0.82, hip BMD 0.79, and femur BMD $0.64 \mathrm{~g} / \mathrm{cm}^{2}$. The ANOVA test found optimal within-group variance concerning mean age, body mass index, and BMD. Greater bALP was associated with lower femoral BMD ( $P=0.01)$. Greater NTx was associated with a greater number of non-vertebral fractures $(P=0.02)$. Greater NTx was associated with greater rate of therapy discontinuation $(P=0.04)$. No other statistically significant associations were detected.
\end{abstract}

Conclusion: Our analysis supports the adoption of BTMs in therapy monitoring of osteoporotic patients.

Level of evidence: Level I, systematic review of RCTs.

Keywords: Osteoporosis, Postmenopausal, Biomarkers, Therapy monitoring

\section{Introduction}

Bone is highly dynamic with resorption and ossification to maintain tissue homeostasis $[1,2]$. Bone alkaline phosphatase (bALP) and procollagen type I N propeptide (PINP) have been considered biomarkers of bone ossification, while serum cross-linked C-telopeptides of

\footnotetext{
* Correspondence: migliorini.md@gmail.com

1 Department of Orthopaedics, University Clinic Aachen, RWTH Aachen University Clinic, Pauwelsstraße 30, 52074 Aachen, Germany

Full list of author information is available at the end of the article
}

type I collagen (bCTx) and urinary cross-linked Ntelopeptides of type I collagen (NTx) are indicators of bone resorption [3-8]. Bone turnover markers (BTMs) highlight the dynamic balance of the bone tissue [4, 9] Markers of ossification (bALP and PINP) derive from the procollagen metabolism or from osteoblasts. Markers of resorption (bCTx and NTx) are produced by osteoclasts or result from collagen degradation processes $[2,4]$. BTMs are influenced by several endogenous factors, such as gender, age, ethnicity, fracture, and

(c) The Author(s). 2021 Open Access This article is licensed under a Creative Commons Attribution 4.0 International License, which permits use, sharing, adaptation, distribution and reproduction in any medium or format, as long as you give appropriate credit to the original author(s) and the source, provide a link to the Creative Commons licence, and indicate if changes were made. The images or other third party material in this article are included in the article's Creative Commons licence, unless indicated otherwise in a credit line to the material. If material is not included in the article's Creative Commons licence and your intended use is not permitted by statutory regulation or exceeds the permitted use, you will need to obtain permission directly from the copyright holder. To view a copy of this licence, visit http://creativecommons.org/licenses/by/4.0/. The Creative Commons Public Domain Dedication waiver (http://creativecommons.org/publicdomain/zero/1.0/) applies to the data made available in this article, unless otherwise stated in a credit line to the data. 
associated diseases [10-13]. Exogenous factors, such as circadian rhythm, seasonal variation, diet, and exercise, also influence BTMs [14-17]. Recently, many studies used BTMs to monitor the efficacy and safety of drugs influencing bone turnover [18-23] and as therapy monitors in postmenopausal osteoporosis [24-26]. Although the use of these biomarkers in clinical practice is common, their role as therapy monitors is still unclear [27, 28]. Indeed, no previous studies performed a systematical evaluation of their potential as therapy monitors in postmenopausal osteoporosis.

The purpose of the study was to explore the potential of bALP, PINP, bCTx, and NTx in therapy monitoring for postmenopausal osteoporosis, investigating their association with bone mineral density (BMD) and the rate of adverse events.

\section{Material and methods}

\section{Search strategy}

This study was conducted according to the Preferred Reporting Items for Systematic Reviews and MetaAnalyses: the PRISMA guidelines [29]. The PICOTD algorithm was preliminarily set out:

- P (Problem): Postmenopausal osteoporosis

- I (Intervention): Therapy monitoring

- C (Comparison): bALP, PINP, bCTx, NTx

- O (Outcomes): BMD, rate of fractures, and adverse events

- T (Timing): Minimum 6 months of follow-up

- D (Design): RCTs

\section{Literature search}

Two independent authors $(* * ; * *)$ performed the literature search in April 2021. The following databases were accessed: PubMed, Google Scholar, EMBASE, and Scopus. No time constrains were used for the search. The following keywords were used in combination: osteoporosis, treatment, management, drug, pharmacology, pharmacological, medicament, mineral, density, bone, $B M D$, bone alkaline phosphatase, ALP, procollagen type I $N$ propeptide, PINP, serum cross-linked C-telopeptides of type I collagen, $C T x$, urinary cross-linked N-telopeptides of type I collagen, NTx, premenopausal, spine, pathological, fragility, fractures, hip, vertebral, disability, adverse events, Calcium, Vitamin D, PTH, osteoblast, and osteoclast. The same authors independently performed the initial screening. If the title and abstract matched the topic, the article full-text was accessed. A cross reference of the bibliographies was also performed to identify further studies.

\section{Eligibility criteria}

All randomized clinical trials (RCTs) comparing two or more pharmacological treatments for postmenopausal osteoporosis were accessed. According to the authors' language capabilities, articles in English, French, German, Italian, Portuguese, and Spanish were eligible. Only level I studies, according to Oxford Centre of EvidenceBased Medicine [30], were considered for inclusion. Only articles reporting quantitative data under the outcomes of interest were eligible. Only clinical studies that reported the amount of bALP, PINP, bCTx, and NTx at last follow-up were included. Articles including patients with secondary osteoporosis were excluded. Studies concerning patients with tumors and/or bone metastases were also not included. Studies reporting data on patients with iatrogenic-induced menopausal and those on pediatric and/ or adolescent patients were not included. Combined therapies with multiple drugs were also not considered in the present study. Studies regarding selected patients undergoing immunosuppressive therapies or organ transplantation were also not considered. Studies with follow-up shorter than 6 months were not eligible, nor where those involving less than 10 patients. Studies reporting data of combined therapy with multiple anti-osteoporotic drugs were also not included. Missing data under these endpoints warranted the exclusion from the present work.

\section{Data extraction and outcomes of interests}

Two authors $(* ; * ; *)$ independently performed data extraction. Study generalities (author, year, journal, duration of the follow-up) and patient baseline demographic information were collected: number of samples and related mean age, mean body mass index (BMI), and mean bone mass index (BMD) of the spine, hip, and femur neck. Data concerning the following endpoints were collected at last follow-up: rate of vertebral, femoral, and hip osteoporotic fractures. Further, data concerning the following complications were collected: serious adverse events and those leading to study discontinuation, gastrointestinal events, musculoskeletal events, and mortality. Data concerning bALP, PINP, bCTx, and NTx were extracted at last follow-up. The ultimate aim was to assess association between biomarkers and clinical outcomes at last follow-up in terms of BMD, rate of pathological fractures, and adverse events.

\section{Methodological quality assessment}

The methodological quality assessment was made through the risk of bias summary tool of the Review Manager Software (The Nordic Cochrane Collaboration, Copenhagen). The following risks of bias were evaluated: selection, detection, performance, reporting, attrition, and other sources of bias. 


\section{Statistical analysis}

The statistical analyses were performed by the main author (**). The IBM SPSS software version 25 was used to assess baseline data. The Shapiro-Wilk test was performed to investigate data distribution. For normal data, mean and standard deviation (SD) were calculated. For non-parametric data, median and interquartile range (IQR) were calculated. The Student $T$-test was used to assess significance for parametric data, while the MannWhitney $U$-test was used for non-parametric variables. Values of $P<0.05$ considered statistically significant. A multivariate analysis was performed to assess associations between biomarkers and clinical outcomes at last follow-up. The STATA Software/MP (StataCorporation, College Station, TX, USA) was used for the statistical analyses. A multiple linear model regression analysis through the Pearson product-moment correlation coefficient $(r)$ was used. The Cauchy-Schwarz formula was used for inequality: +1 was considered as positive linear correlation, and -1 a negative one. Values of $0.1<|r|<$ $0.3,0.3<|r|<0.5$, and $|r|>0.5$ were considered to have weak, moderate, and strong correlation, respectively. The overall significance was performed through the $X^{2}$ test, with values of $P<0.05$ considered statistically significant.

\section{Results}

\section{Search result}

The literature search resulted in 1174 studies. Of them, 307 were duplicates. A further 749 articles were excluded because of nature of the study $(N=233)$, nonclinical studies $(N=301)$, secondary osteoporosis $(N=$ $81)$, small population or short follow-up $(N=19)$, multiple therapies $(N=21)$, language limitations $(N=9)$, uncertain results $(N=13)$, and others $(N=72)$. Another 102 articles were excluded because data under the outcomes of interest were missing. Finally, 16 RCTs were eligible for inclusion in the present study (Fig. 1).

\section{Methodological quality assessment}

The inclusion of only RCTs yields to low risk of selection bias. Many studies performed patients and assessor blinding, thus leading to moderate-low risk of detection and performance biases. The overall high quality of the included studies led also to an overall low-risk of attrition and reporting bias. Overall, the results of the evaluation of each risk of bias item for each individual study included in the present analysis was low to moderate, leading to a good assessment of the methodology. The risk of bias graph is shown in Fig. 2.

\section{Patient demographics}

A total of 14,446 patients were included. The median age was 67 (IQR 4.7), and the median BMI 25.4 (IQR
1.9). The median vertebral BMD was 0.82 (IQR 0.14), hip BMD 0.79 (IQR 0.1), and femur BMD 0.64 (IQR 0.02). The ANOVA test found optimal within-group variance concerning mean age, $\mathrm{BMI}$, and $\mathrm{BMD}(P>0.1)$. Generalities and patient baseline data of the included studies are shown in detail in Table 1.

\section{Outcomes of interest}

Greater bALP was associated with lower femoral BMD $(r=-0.87 ; P=0.01)$. Greater NTx was associated with greater of occurrence of non-vertebral fractures $(r=$ $0.98 ; P=0.02)$. Greater NTx was associated with greater rate of therapy discontinuation $(r=-0.60 ; P=0.04)$. There was evidence of positive association between PINP and CTx $(r=-0.93 ; P=0.0001)$. No other statistically significant associations were detected. These results are shown in Table 2. Added-variable plots of the statistically significant outcomes are displayed in Fig. 3.

\section{Discussion}

Our findings suggest that bALP and NTx may represent useful, valid, and reliable tools for therapy monitoring for postmenopausal osteoporotic patients. Higher bALP and NTx were associated to lower femoral BMD and higher rate of non-vertebral fractures, respectively. Furthermore, a positive association between NTx and the rate of adverse events leading to therapy discontinuation was evidenced. BTMs are implicated in bone turnover, and their level significantly varies during osteoporotic therapy [31, 33, 37, 38, 45]. P1NP and bCTx did not show any statistically significant association with any of the considered variables in the present study. PINP is released following to the amino/carboxy-terminal extensions cleavage of the procollagen and can be found variably in the blood [46]. bCTx is a form of the telopeptides of type I collagen released during collagen degradation [7, 47]. We were unable to find any significant association for these two BTMs; thus, their potential in therapy monitoring remains uncertain.

Given their sensibility to reveal changes in bone turnover, BTMs gained popularity [3, 22, 23]. BTMs' variations related also to antiresorptive drugs, which produce a quick decrease of the bone resorption markers, followed by those of bone formation [48]. Vice versa, anabolic drugs increase the level of bone formation markers, followed by those of bone resorption [45]. BTMs' changes are related to the risk of fragility fractures; thus, BTMs have been introduced to monitor therapy in osteoporotic patients $[49,50]$. The effect of the therapy on BTMs strictly depends on the type of drug used [45]. Antiresorptive drugs inhibit osteoclasts and cause a rapid reduction in resorption markers, followed by a reduction in bone formation markers [45]. Indeed, the present study shows an association between 

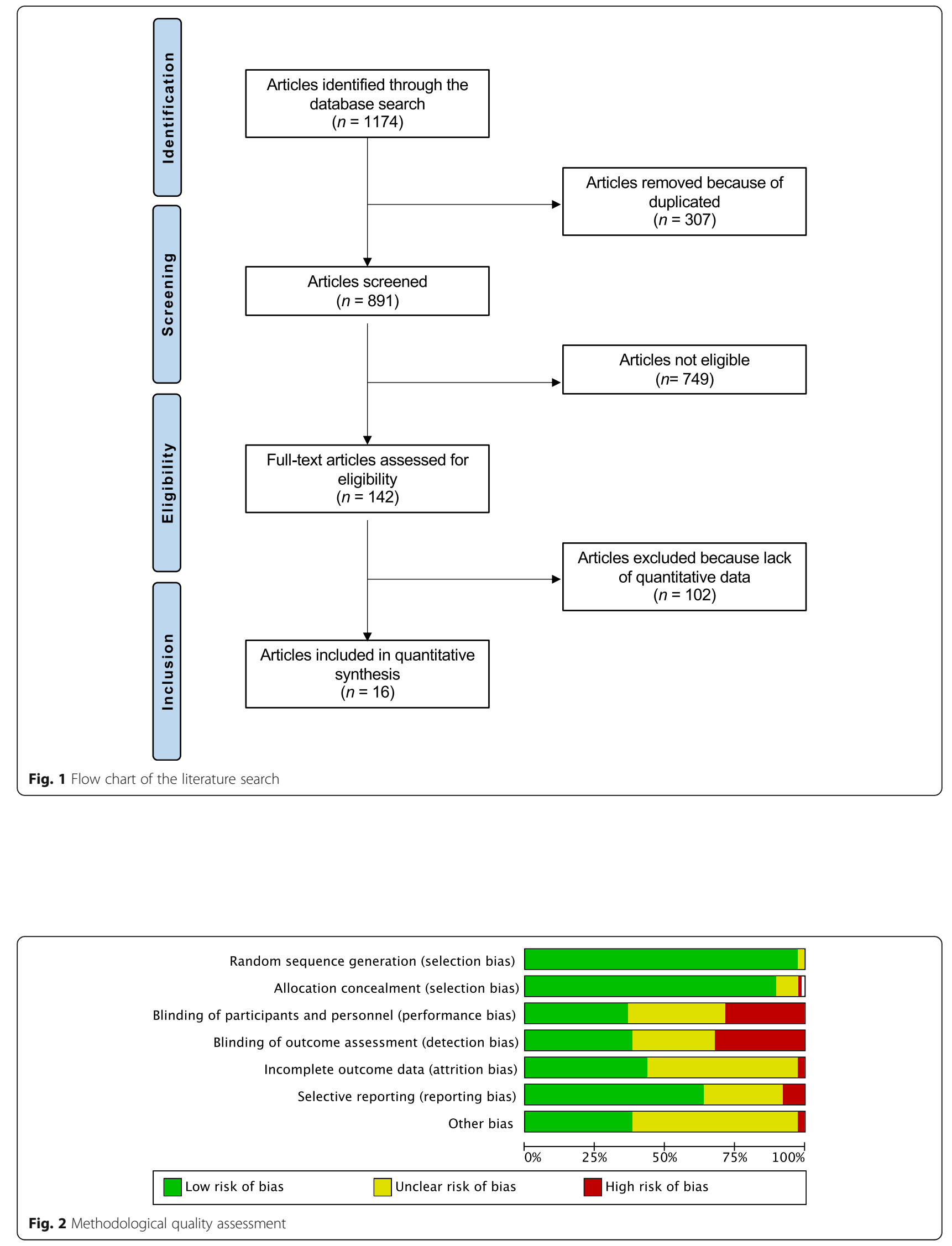


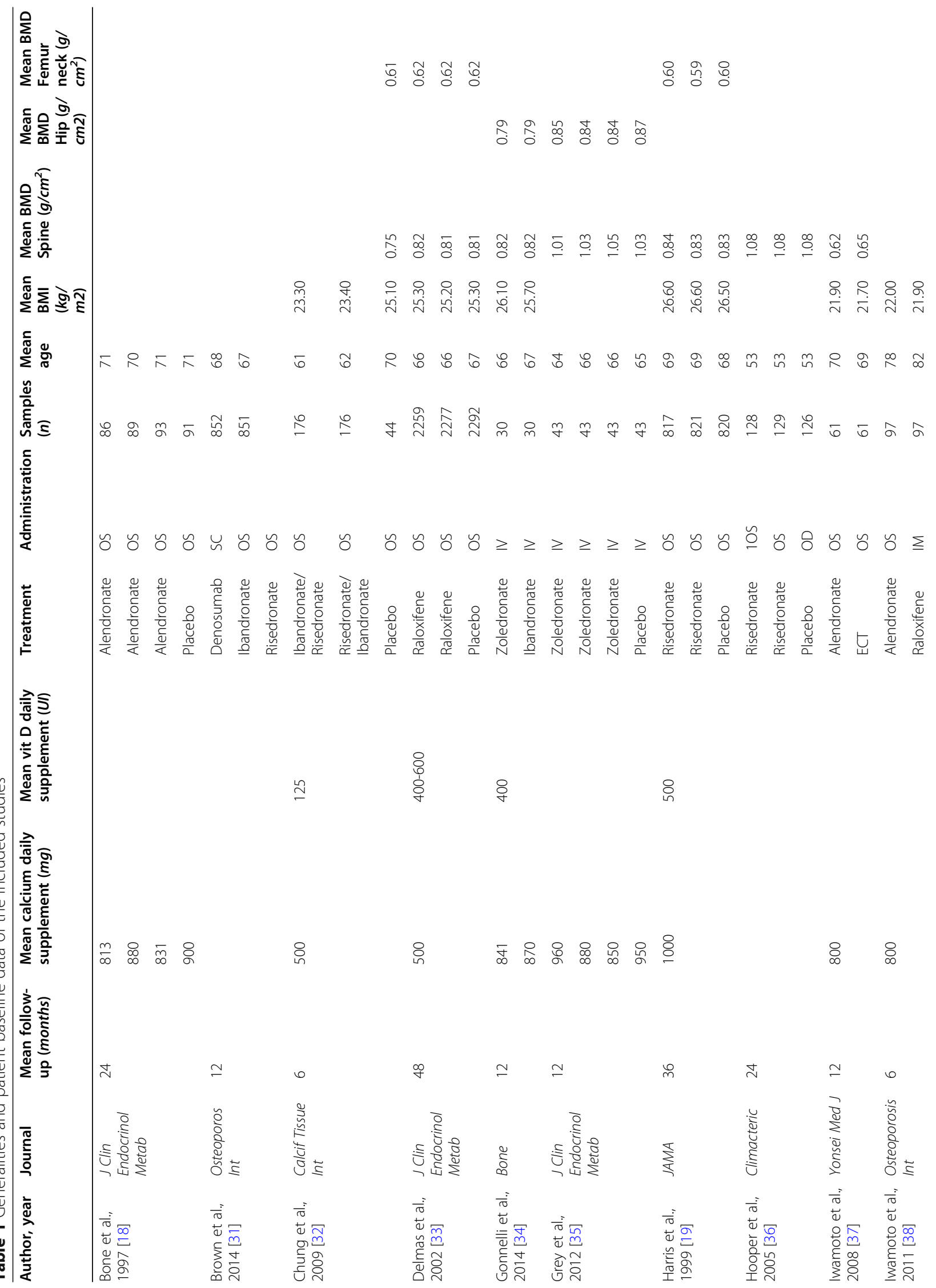




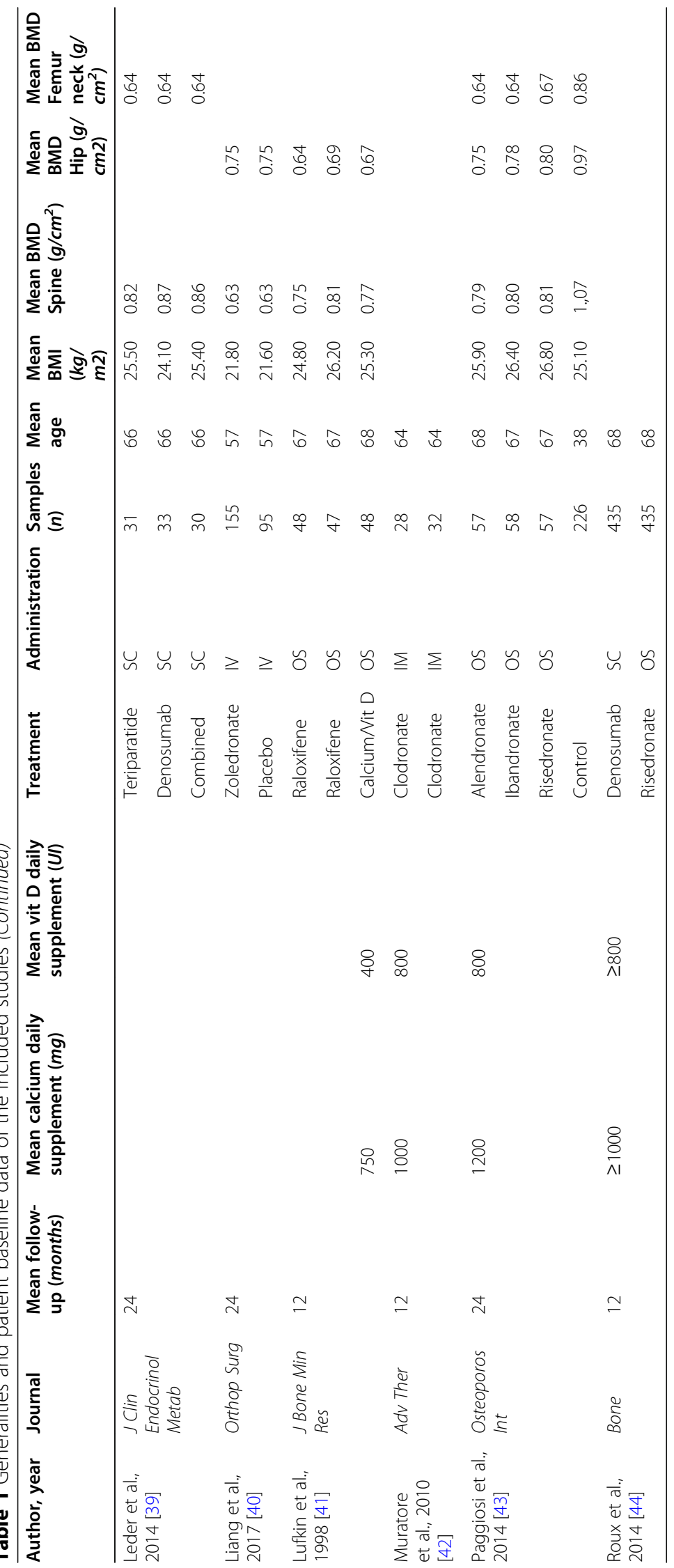


Table 2 Overall results of the multivariate analysis

\begin{tabular}{|c|c|c|c|c|c|c|c|c|}
\hline \multirow[t]{2}{*}{ Endpoint } & \multicolumn{2}{|c|}{ bALP } & \multicolumn{2}{|l|}{ NTx } & \multicolumn{2}{|c|}{ bCTx } & \multicolumn{2}{|c|}{ PINP } \\
\hline & $P$ & $r$ & $P$ & $r$ & $P$ & $r$ & $P$ & $r$ \\
\hline BMD spine & 0.6 & 0.16 & 0.06 & -0.59 & 0.9 & 0.0 & 1.0 & 0.00 \\
\hline BMD hip & 0.5 & 0.40 & 0.3 & -0.83 & 0.9 & 0.0 & 0.8 & -0.13 \\
\hline BMD femur & 0.01 & -0.87 & 0.4 & -0.29 & 0.6 & -0.3 & 1.0 & -1.00 \\
\hline Non-vertebral fractures & 0.2 & -0.41 & 0.02 & 0.98 & 1.0 & -1.0 & & \\
\hline Vertebral fractures & 0.6 & -0.18 & 0.5 & 0.29 & & & & \\
\hline Femur fractures & & & & & 1.0 & -1.0 & & \\
\hline Hip fractures & & & & & 1.0 & -1.0 & & \\
\hline Adverse events & 0.08 & -0.65 & 0.5 & -0.44 & 0.9 & 0.0 & 0.3 & -0.58 \\
\hline Serious adverse events & & & 0.5 & 0.68 & 0.7 & -0.3 & & \\
\hline Therapy discontinuation & 0.2 & -0.46 & 0.04 & -0.60 & 0.4 & -0.4 & 0.5 & -0.55 \\
\hline Gastrointestinal adverse events & 0.5 & -0.40 & 0.8 & -0.25 & 0.2 & -0.9 & 0.2 & -0.97 \\
\hline Musculoskeletal adverse events & 0.1 & -0.99 & & & 0.9 & 0.0 & 0.8 & -0.15 \\
\hline Mortality & & & & & 1.00 & -1.0 & & \\
\hline
\end{tabular}

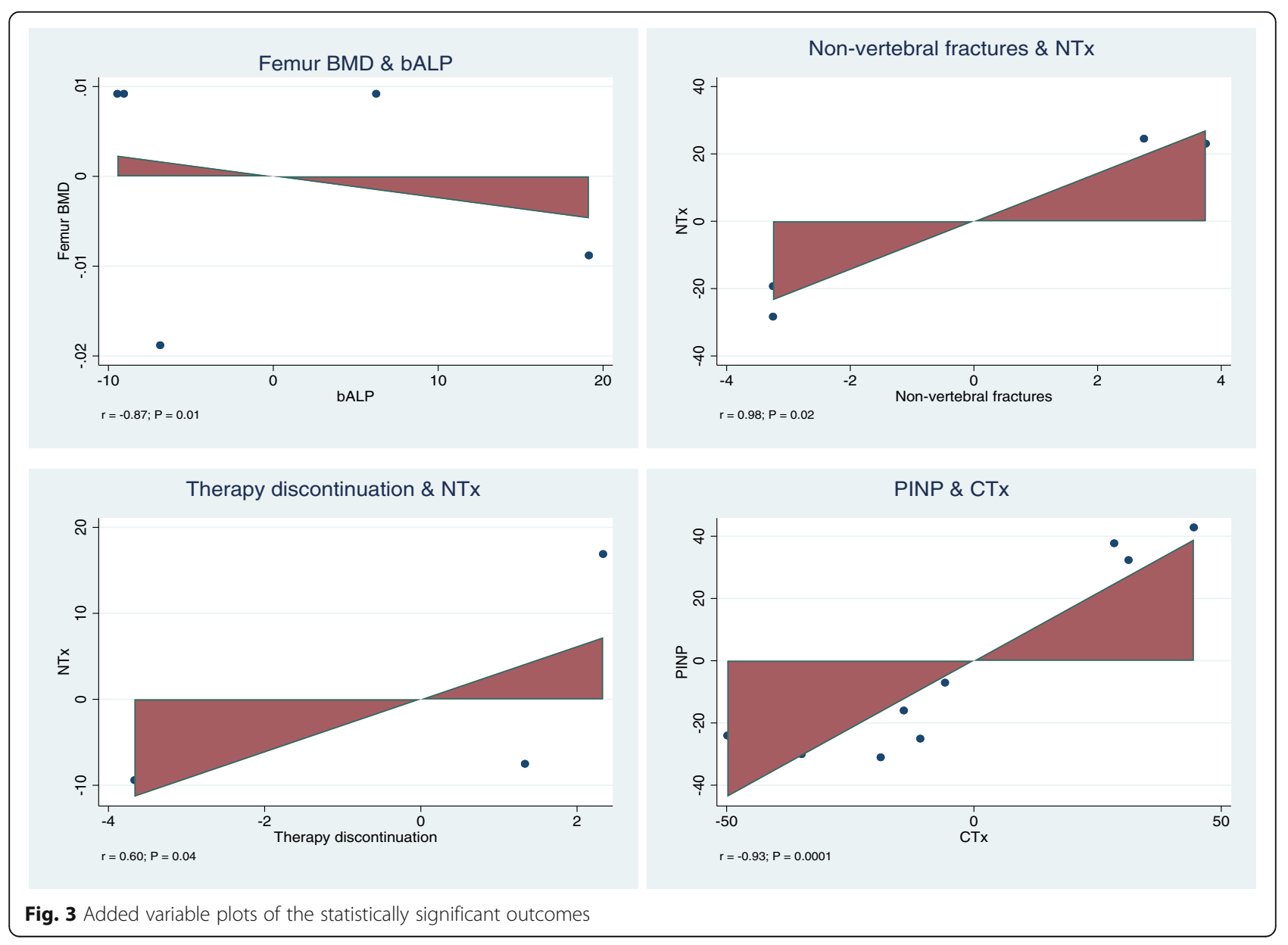


BMD and bALP. BALP is a membrane-bound enzyme found in almost all tissues of the organism and can be easily measured in serum [51]. bALP has been the first BTMs of bone turnover intensively investigated [52]. It was initially used to monitor the efficacy and safety of some drugs acting on bone turnover, and subsequently acquired popularity to monitor therapy in osteoporotic patients [53, 54]. Bjarnason et al. [55] found that bALP had stronger association than BMD to predict the risk of fragility fractures in patients undergoing raloxifene therapy. These results were unexpected, since BMD was considered a very reliable measure of the risk of fractures [56, 57]. Similar results were found by Iwamoto et al. [38] and Gonnelli et al. [34] evaluating the outcome of alendronate zoledronate and ibandronate on patients' quality of life. Both studies evidenced a statistically significant association between the increase in BMD and a decrease in serum bALP levels. Comparable results were obtained by Delmas et al. [33], evaluating the efficacy of raloxifene in preventing vertebral fracture in patients with postmenopausal osteoporosis. Muratore et al. [42] found that the bALP and BMD variations were proportional to the dose of clodronate administered to patients. Overall, these findings encouraged the use of bALP to monitor therapy in patients undergoing pharmacological management of postmenopausal osteoporosis [42].

Our analyses showed evidence of positive association between NTx and the rate of non-vertebral fractures. NTx and bCTX are two different forms of the telopeptide of type I collagen, which modulate the degradation process of collagen $[7,47]$. These telopeptides are measurable in serum and in the urines and exhibit to circadian cycle variations [58, 59]. Iwamoto et al. [38] demonstrated that alendronate reduced the urinary level of NTx [38]. Garnero et al. [60] found that the urinary excretion of NTx did not predict fractures, hypothesizing that it follows a different pattern of bone collagen degradation.

This study shows limitations. The analyses were performed regardless to the drug type and administration. This enhanced the risk of bias of the present study, negatively affecting the reliability of our results. Furthermore, the heterogeneous daily administration of vitamin $\mathrm{D}$ and calcium represents another important limitation. We included only RCTs reporting quantitative data under the outcomes of interest, which were published in peer reviewed scientific. However, the role of BTMs has been poorly investigated, and none of the included articles did not aim to quantify directly the biomarkers' variations. Results from this study should encourage future investigation to evaluate the potential of BTMs in a clinical setting, analyzing their variations as primary outcome. The biological variability of BTMs constitutes an important factor limiting their engagement in the management of osteoporosis.

\section{Conclusion}

The analysis of BTMs in the investigation of their possible role in monitoring therapy demonstrates the need for studies that can validate their use in clinical practice. Our analysis supports the adoption of BTMs in therapy monitoring of postmenopausal osteoporosis patients. Further studies are needed to analyze variations of BTMs in relation to treatment as a primary outcome.

\section{Abbreviations \\ BTMs: Biochemical markers of bone turnover; bALP: Bone alkaline phosphatase; PINP: Procollagen type I N propeptide; bCTx: Serum cross- linked C-telopeptides of type I collagen; NTx: Urinary cross-linked N- telopeptides of type I collagen; RCTs: Randomized clinical trials; BMI: Bone mass index; BMD: Bone mineral density}

\section{Acknowledgements}

None

\section{Authors' contributions}

FM: literature search, data extraction, methodological quality assessment, statistical analyses, writing; NM: supervision, revision, final approval; RG: literature search, data extraction, methodological quality assessment; FS: revision; PGM, MT: supervision. The authors read and approved the final manuscript.

\section{Funding}

No external source of funding was used. Open Access funding enabled and organized by Projekt DEAL.

\section{Availability of data and materials}

This study does not contain any third material.

\section{Declarations}

Ethics approval and consent to participate

This article does not contain any studies with human participants or animals performed by any of the authors.

Consent for publication

All the authors approved the manuscript.

\section{Competing interests}

The authors declare that they have no conflicts of interest.

\section{Author details}

${ }^{1}$ Department of Orthopaedics, University Clinic Aachen, RWTH Aachen University Clinic, Pauwelsstraße 30, 52074 Aachen, Germany. ²Department of Medicine, Surgery and Dentistry, University of Salerno, Via S. Allende, 84081 Baronissi, SA, Italy. ${ }^{3}$ School of Pharmacy and Bioengineering, Keele University Faculty of Medicine, Thornburrow Drive, Stoke on Trent, England. ${ }^{4}$ Centre for Sports and Exercise Medicine, Mile End Hospital, Barts and the London School of Medicine and Dentistry, Queen Mary University of London, 275 Bancroft Road, London E1 4DG, England. ${ }^{5}$ Department of Orthopedics and Trauma Surgery, Ospedale San Carlo Potenza, Via Potito Petrone, Potenza, Italy. ${ }^{6}$ Department of Biomedical Sciences for Health, University of Milan, Milan, Italy. ${ }^{7}$ Orthopedics and Traumatology, University of Milan, IRCCS Istituto Ortopedico Galeazzi, Milan, Italy. 
Received: 21 April 2021 Accepted: 6 May 2021

\section{Published online: 18 May 2021}

\section{References}

1. Florencio-Silva R, Sasso GR, Sasso-Cerri E, et al. Biology of bone tissue: structure, function, and factors that influence bone cells. Biomed Res Int. 2015;2015:421746.

2. Hill PA. Bone remodelling. Br J Orthod. 1998;25:101-7.

3. Hlaing $T$, Compston JE. Biochemical markers of bone turnover - uses and limitations. Ann Clin Biochem. 2014;51:189-202.

4. Christenson $\mathrm{RH}$. Biochemical markers of bone metabolism: an overview. Clin Biochem. 1997;30:573-93.

5. Samoszuk M, Leuther $M$, Hoyle N. Role of serum P1NP measurement for monitoring treatment response in osteoporosis. Biomark Med. 2008;2:495508.

6. Parfitt AM. Bone histomorphometry: standardization of nomenclature, symbols and units (summary of proposed system). Bone. 1988;9:67-9.

7. Garnero P, Buchs N, Zekri J, et al. Markers of bone turnover for the management of patients with bone metastases from prostate cancer. $\mathrm{Br} J$ Cancer. 2000;82:858-64.

8. Ju HS, Leung S, Brown B, et al. Comparison of analytical performance and biological variability of three bone resorption assays. Clin Chem. 1997;43: 1570-6

9. Bauer DC, Garnero P, Harrison SL, et al. Biochemical markers of bone turnover, hip bone loss, and fracture in older men: the MrOS study. J Bone Miner Res. 2009;24:2032-8.

10. Mora S, Prinster C, Proverbio MC, et al. Urinary markers of bone turnover in healthy children and adolescents: age-related changes and effect of puberty. Calcif Tissue Int. 1998;63:369-74.

11. Pratt JH, Manatunga AK, Peacock M. A comparison of the urinary excretion of bone resorptive products in white and black children. J Lab Clin Med. 1996;127:67-70.

12. Ingle BM, Hay SM, Bottjer HM, et al. Changes in bone mass and bone turnover following distal forearm fracture. Osteoporos Int. 1999;10:399-407.

13. Christensen JO, Svendsen OL. Bone mineral in pre- and postmenopausal women with insulin-dependent and non-insulin-dependent diabetes mellitus. Osteoporos Int. 1999;10:307-11.

14. Seibel MJ. Biochemical markers of bone turnover: part I: biochemistry and variability. Clin Biochem Rev. 2005;26:97-122.

15. Woitge HW, Scheidt-Nave C, Kissling C, et al. Seasonal variation of biochemical indexes of bone turnover: results of a population-based study. J Clin Endocrinol Metab. 1998;83:68-75.

16. Hannon R, Eastell R. Preanalytical variability of biochemical markers of bone turnover. Osteoporos Int. 2000;11(Suppl 6):S30-44.

17. Takahashi M, Kawana K, Nagano A. Biological variability of biochemical markers of bone turnover in healthy women. Endocr Res. 2002;28:257-64.

18. Bone HG, Downs RW Jr, Tucci JR, et al. Dose-response relationships for alendronate treatment in osteoporotic elderly women. Alendronate Elderly Osteoporosis Study Centers. J Clin Endocrinol Metab. 1997;82:265-74.

19. Harris ST, Watts NB, Genant HK, et al. Effects of risedronate treatment on vertebral and nonvertebral fractures in women with postmenopausal osteoporosis: a randomized controlled trial. Vertebral Efficacy With Risedronate Therapy (VERT) Study Group. JAMA. 1999;282:1344-52.

20. Delmas PD, Eastell R, Garnero P, et al. The use of biochemical markers of bone turnover in osteoporosis. Committee of Scientific Advisors of the International Osteoporosis Foundation. Osteoporos Int. 2000;11(Suppl 6):S2-17.

21. Civitelli R, Armamento-Villareal R, Napoli N. Bone turnover markers: understanding their value in clinical trials and clinical practice. Osteoporos Int. 2009;20:843-51.

22. Jain S, Camacho P. Use of bone turnover markers in the management of osteoporosis. Curr Opin Endocrinol Diabetes Obes. 2018;25:366-72.

23. Eastell R, Pigott T, Gossiel F, et al. Diagnosis of endocrine disease: bone turnover markers: are they clinically useful? Eur J Endocrinol. 2018:178:R19-31.

24. Bell KJ, Hayen A, Irwig $L$, et al. The potential value of monitoring bone turnover markers among women on alendronate. J Bone Miner Res. 2012; 27:195-201.

25. Eastell $R$, Szulc $P$. Use of bone turnover markers in postmenopausal osteoporosis. Lancet Diabetes Endocrinol. 2017:5:908-23.

26. Lorentzon M, Branco J, Brandi ML, et al. Algorithm for the use of biochemical markers of bone turnover in the diagnosis, assessment and follow-up of treatment for osteoporosis. Adv Ther. 2019;36:2811-24.
27. Greenblatt MB, Tsai JN, Wein MN. Bone turnover markers in the diagnosis and monitoring of metabolic bone disease. Clin Chem. 2017; 63:464-74.

28. Tian A, Ma J, Feng $K$, et al. Reference markers of bone turnover for prediction of fracture: a meta-analysis. J Orthop Surg Res. 2019;14:68.

29. Moher D, Liberati A, Tetzlaff J, et al. Preferred reporting items for systematic reviews and meta-analyses: the PRISMA statement. BMJ. 2009;339:b2535.

30. Howick J Cl, Glasziou P, Greenhalgh T, Carl Heneghan, Liberati A, Moschetti I, Phillips B, Thornton H, Goddard O, Hodgkinson M. The 2011 Oxford CEBM Levels of Evidence. Oxford Centre Evid Based Med. 2011. Available at https://www.cebmnet/indexaspx?o=5653. Accessed Jan 2021.

31. Brown JP, Roux C, Ho PR, et al. Denosumab significantly increases bone mineral density and reduces bone turnover compared with monthly oral ibandronate and risedronate in postmenopausal women who remained at higher risk for fracture despite previous suboptimal treatment with an oral bisphosphonate. Osteoporos Int. 2014;25:1953-61.

32. Chung YS, Lim SK, Chung HY, et al. Comparison of monthly ibandronate versus weekly risedronate in preference, convenience, and bone turnover markers in Korean postmenopausal osteoporotic women. Calcif Tissue Int. 2009;85:389-97.

33. Delmas PD, Ensrud KE, Adachi JD, et al. Efficacy of raloxifene on vertebral fracture risk reduction in postmenopausal women with osteoporosis: fouryear results from a randomized clinical trial. J Clin Endocrinol Metab. 2002; 87:3609-17.

34. Gonnelli S, Caffarelli C, Tanzilli L, et al. Effects of intravenous zoledronate and ibandronate on carotid intima-media thickness, lipids and FGF-23 in postmenopausal osteoporotic women. Bone. 2014;61:27-32.

35. Grey A, Bolland M, Wong S, et al. Low-dose zoledronate in osteopenic postmenopausal women: a randomized controlled trial. J Clin Endocrinol Metab. 2012;97:286-92.

36. Hooper MJ, Ebeling PR, Roberts AP, et al. Risedronate prevents bone loss in early postmenopausal women: a prospective randomized, placebocontrolled trial. Climacteric. 2005;8:251-62.

37. Iwamoto J, Sato $Y$, Uzawa M, et al. Comparison of effects of alendronate and raloxifene on lumbar bone mineral density, bone turnover, and lipid metabolism in elderly women with osteoporosis. Yonsei Med J. 2008;49: 119-28.

38. Iwamoto J, Makita $K$, Sato $Y$, et al. Alendronate is more effective than elcatonin in improving pain and quality of life in postmenopausal women with osteoporosis. Osteoporos Int. 2011;22:2735-42.

39. Leder BZ, Tsai JN, Uihlein AV, et al. Two years of Denosumab and teriparatide administration in postmenopausal women with osteoporosis (The DATA Extension Study): a randomized controlled trial. J Clin Endocrinol Metab. 2014;99:1694-700.

40. Liang BC, Shi ZY, Wang B, et al. Intravenous zoledronic acid $5 \mathrm{mg}$ on bone turnover markers and bone mineral density in East China subjects with newly diagnosed osteoporosis: a 24-month clinical study. Orthop Surg. 2017;9:103-9.

41. Lufkin EG, Whitaker MD, Nickelsen T, et al. Treatment of established postmenopausal osteoporosis with raloxifene: a randomized trial. J Bone Miner Res. 1998;13:1747-54.

42. Muratore M, Quarta L, Calcagnile F, et al. "Twice-a-month" clodronate $200 \mathrm{mg}$ IM: a new dosing regimen and improved therapy adherence in the treatment of postmenopausal osteoporosis. Adv Ther. 2010;27:31420.

43. Paggiosi MA, Peel N, McCloskey E, et al. Comparison of the effects of three oral bisphosphonate therapies on the peripheral skeleton in postmenopausal osteoporosis: the TRIO study. Osteoporos Int. 2014;25: 2729-41.

44. Roux C, Hofbauer LC, Ho PR, et al. Denosumab compared with risedronate in postmenopausal women suboptimally adherent to alendronate therapy: efficacy and safety results from a randomized open-label study. Bone. 2014; 58:48-54.

45. Vasikaran S, Eastell R, Bruyere $\mathrm{O}$, et al. Markers of bone turnover for the prediction of fracture risk and monitoring of osteoporosis treatment: a need for international reference standards. Osteoporos Int. 2011;22:391-420.

46. Ryder KM, Tanner SB, Carbone L, et al. Teriparatide is safe and effectively increases bone biomarkers in institutionalized individuals with osteoporosis. J Bone Miner Metab. 2010;28:233-9. 
47. Garnero P, Cloos P, Sornay-Rendu E, et al. Type I collagen racemization and isomerization and the risk of fracture in postmenopausal women: the OFELY prospective study. J Bone Miner Res. 2002;17:826-33.

48. Eastell R, Barton I, Hannon RA, et al. Relationship of early changes in bone resorption to the reduction in fracture risk with risedronate. J Bone Miner Res. 2003;18:1051-6.

49. Bauer DC, Black DM, Garnero P, et al. Change in bone turnover and hip, non-spine, and vertebral fracture in alendronate-treated women: the fracture intervention trial. J Bone Miner Res. 2004;19:1250-8.

50. Sarkar S, Reginster JY, Crans GG, et al. Relationship between changes in biochemical markers of bone turnover and BMD to predict vertebral fracture risk. J Bone Miner Res. 2004;19:394-401.

51. Garnero P, Delmas PD. Assessment of the serum levels of bone alkaline phosphatase with a new immunoradiometric assay in patients with metabolic bone disease. J Clin Endocrinol Metab. 1993;77:1046-53.

52. Parfitt AM, Drezner MK, Glorieux FH, et al. Bone histomorphometry: standardization of nomenclature, symbols, and units. Report of the ASBMR Histomorphometry Nomenclature Committee. J Bone Miner Res. 1987;2: 595-610.

53. Yao S, Laurent CA, Roh JM, et al. Serum bone markers and risk of osteoporosis and fragility fractures in women who received endocrine therapy for breast cancer: a prospective study. Breast Cancer Res Treat. 2020;180:187-95

54. Williams C, Sapra A. Osteoporosis Markers. Treasure Island: StatPearls; 2020.

55. Bjarnason NH, Sarkar S, Duong T, et al. Six and twelve month changes in bone turnover are related to reduction in vertebral fracture risk during 3 years of raloxifene treatment in postmenopausal osteoporosis. Osteoporos Int. 2001;12:922-30.

56. Lorentzon M. Treating osteoporosis to prevent fractures: current concepts and future developments. J Intern Med. 2019;285:381-94.

57. Alarkawi $D$, Bliuc D, Nguyen TV, et al. Contribution of lumbar spine BMD to fracture risk in individuals with T-score discordance. J Bone Miner Res. 2016; 31:274-80.

58. Simon LS, Krane SM, Wortman PD, et al. Serum levels of type I and III procollagen fragments in Paget's disease of bone. J Clin Endocrinol Metab. 1984;58:110-20.

59. Christgau S. Circadian variation in serum CrossLaps concentration is reduced in fasting individuals. Clin Chem. 2000;46:431.

60. Garnero P, Hausherr E, Chapuy MC, et al. Markers of bone resorption predict hip fracture in elderly women: the EPIDOS Prospective Study. J Bone Miner Res. 1996;11:1531-8.

\section{Publisher's Note}

Springer Nature remains neutral with regard to jurisdictional claims in published maps and institutional affiliations.

Ready to submit your research? Choose BMC and benefit from:

- fast, convenient online submission

- thorough peer review by experienced researchers in your field

- rapid publication on acceptance

- support for research data, including large and complex data types

- gold Open Access which fosters wider collaboration and increased citations

- maximum visibility for your research: over $100 \mathrm{M}$ website views per year

At $\mathrm{BMC}$, research is always in progress.

Learn more biomedcentral.com/submissions 